\title{
Treatment of Fractures of the Shaft of the Femur in Children by Ender`s Nails: A Prospective Study in Kashmiri Children
}

\author{
Maajid Shabeer Peerzada ${ }^{1}$, Nayyar Andildar Malik ${ }^{2}$ \\ ${ }^{1}$ Post Graduate Scholar Department of orthopaedics GMC Srinagar, J \& K, India \\ ${ }^{2}$ Post Graduate scholar department of anaesthesia SKIMS Srinagar, J \& K, India
}

\begin{abstract}
We did a prospective study of 20 cases on treatment of fracture shaft of femur in children by Ender's nail. The average duration of hospital stay was 9 days. Femoral shaft fractures in children can be operatively treated with excellent results and a decreased complication rate. Operation results in shorter hospitalization which has psychological, social, educational, and economic advantages over conservative treatment.
\end{abstract}

Keywords: edners nail, fracture, femur, shaft

\section{Introduction}

Automobile accidents account for $90 \%$ of femoral shaft fractures in children. These fractures caused by road traffic accidents frequently have associated injuries. In the past, traction and hip spica was the standard treatment for all femoral shaft fractures which involved long duration of hospitalization. More recently, a variety of therapeutic alternatives such as intramedullary nailing and dynamic compression plating have become available to decrease impairment, increase convenience \& decrease cost of care ${ }^{1}$ The management of femoral shaft fractures in children has evolved towards more operative approaches in the last two decades to minimize the post plaster complications.

Operative management of fracture shaft femur in children is becoming a preferred option because of fact that there is decrease in incidence of malunion, short hospital stay, lesser surgical cost, better nursing care and early ambulation ${ }^{2}$.

\section{Material \& Methods}

20 patients aged 5 to $15 \mathrm{yrs}$ with fresh fracture shaft femur from a point $5 \mathrm{~cm}$ distal to lesser trochanter to supracondylar ridge of femur were considered eligible for this study. Fractures whether simple, transverse, oblique, spiral or comminuted were included in the study. The study was conducted from January 2013 to january 2014 in post graduate department of orthopaedics GMC Srinagar. Patients were initially resuscitated as per ATLS protocol. Fractured limb was splinted in long leg crammer wire. Analgesics and antibiotics were given accordingly. Radiographic examination was done in both anteroposterior and lateral views. Patients were operated in the routine operation list after 24 hours.

\section{Operative Technique}

On a fracture table, traction was applied under image intensifier guidance to reduce the fracture. The number of nails was determined by the width of medullary canal at the isthmus, with 1 nail for each $5 \mathrm{~mm}$ of medullary canal. The longest nail that will not encroach on the greater trochanter and capital femoral epiphysis was used. One concave and one "S curved "nail gives the best fixation. After incising the skin, insertion points were made one on posteromedial and another on posterolateral side of distal femur 2 to $3 \mathrm{~cm}$ proximal to the distal epiphyseal plate. The Ender nails were driven across the fracture site one at a time. The nails were rotated and bent so that tip of one is just distal to greater trochanter and the other is distal to the capital femoral epiphysis. Two divergent Ender nails provide adequate fixation and stability. Rotational alignment was checked before final impaction of the nails. wound was closed and antisepttic dressing was done. Post operatively antibiotics were continued.

\section{Results}

Between January 2013 to January 2014, 20 patients with femoral shaft fractures with age between 5 to $15 \mathrm{yrs}$ were treated with Ender nails. There were $15(75 \%)$ boys and $5(25 \%)$ girls. The mode of injury was road traffic accident in $16(80 \%)$ and fall in $4(20 \%)$ of children. $12(60 \%)$ cases sustained right sided and $8(40 \%)$ cases sustained left sided fracture. There were $4(20 \%)$ fractures in proximal third, 15 $(75 \%)$ in middle third, $1(5 \%)$ in distal third. $18(90 \%)$ fractures were of closed type and $2(10 \%)$ were compound fractures.

$11(55 \%)$ cases had transverse fracture, $5(25 \%)$ had oblique fracture, $2(10 \%)$ had comminuted fracture and $2(10 \%)$ had spiral fracture. Associated injuries were seen in $20 \%$ cases of which 1 patient had head injury and ipsilateral tibial fracture.

Postoperatively no patient needed any protective splint. Knee bending and quadriceps strengthening exercises were begun as soon as the patient was comfortable. Non-weight bearing crutch walking was started after 2 to 3 weeks provided the muscle control of the leg was obtained and child was intelligent enough to understand it. After 3 weeks, partial weight bearing was allowed. 


\section{International Journal of Science and Research (IJSR) \\ ISSN (Online): 2319-7064 \\ Index Copernicus Value (2013): 6.14 | Impact Factor (2014): 5.611}

Final results were assessed according to criteria's given by Pati et al 8 . The final results in our study were excellent in 19 $(95 \%)$ cases and good in $1(5 \%)$ case.

Our series matched with Heinrich et al (1982) who have also demonstrated excellent results with flexible intramedullary nailing.

Our series matched with Ligier et al ${ }_{4}$ (1988) who showed excellent results with Ender's nail with minimum complications.

Mann et al 5 (1986) also demonstrated excellent results with $100 \%$ union rate without any angular malunions or leg length discrepancies.

Ozturkmen $\mathrm{Y}$ et al 7 (2002) also demonstrated excellent results with Ender's nail with no limb length discrepancy in $80 \%$ of patients and no observation regarding delayed union, infection, nonunion, growth arrest, refracture after rod removal. The average duration of fracture union was 8.5 weeks. In our series the average duration of hospital stay was 9 days.

\section{Complications}

In our study there were very few complications. Three patients had Limb length discrepancy, 1 case had overgrowth of $0.5 \mathrm{~cm}$ and another up to $0.5-2.0 \mathrm{cms}$. 1 case had shortening of $7 \mathrm{~mm}$ due to shortening in the tibial component because of segmental ipsilateral tibia fracture. The rest 17 (85\%) had no limb length discrepancy. There were $2(10 \%)$ cases having angulation each of less than 10 ? There was no case having rotational deformity. $1(5 \%)$ case had distal migration of nail after 6 months, which was removed. 1 case developed knee stiffness as the patient was having associated head injury along with ipsilateral tibia fracture which was managed with plaster cast and internal fixation was delayed.

Although the patient had to buy the Ender's nails from the market but the cost was less because of shorter hospitalization. The nails are also cheaper as compared to

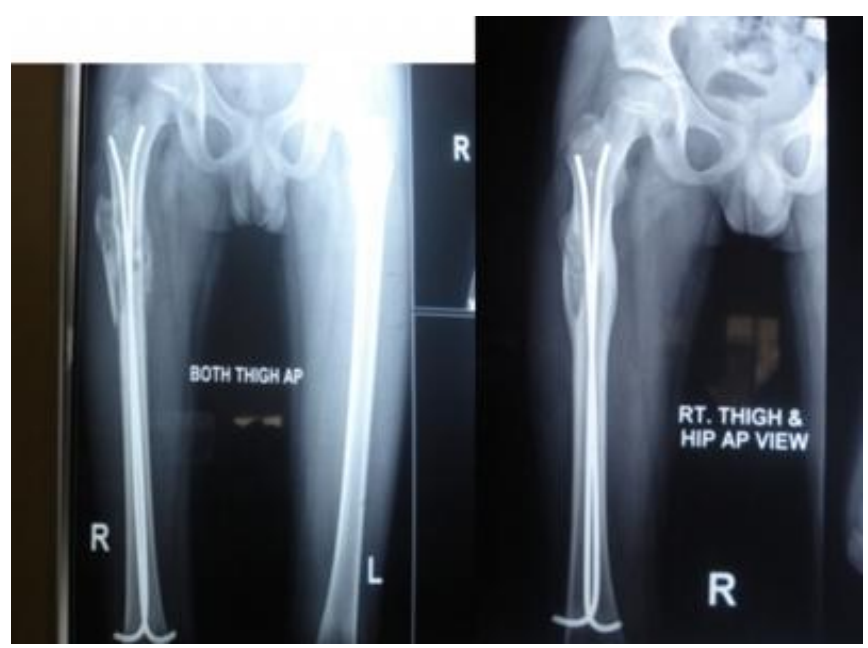

other implants. Some of the patients had come from distant places leading to increased expense in cases of longer hospital stay. Some of the patients were deprived of the family environment and were repeatedly asking for discharge from the hospital. So the operative treatment with Ender's nail according to our study was more cost effective.

\section{Discussion}

The ideal treatment of femoral shaft fracture in children is defined as one that controls alignment and length, is comfortable for child and convenient for family and causes the least psychological impact possible . $_{\text {. }}$

In the present study, the children from 5-15 years of age were treated with Ender's nail for femoral shaft fractures. The closed retrograde Ender nailing of femoral shaft fracture appears to be the ideal technique. Operative reduction and stabilisation with this technique is safe without danger to growth plates and device is easily inserted and removed Enders nail is a semi-elastic internal fixation device which is sufficient to hold fracture fragments in anatomic alignment. The slight motion permitted by Enders nail stimulates formation of large external callus not seen with rigid fixation. It has been shown that external callus provides the most rapid restoration of continuity and strength of fracture diaphysis.

Enders nail is a safe and satisfactory mode of fixation which is relatively easy to perform.

So it is felt that operative treatment with Enders nail has greatly decreased hospital stay, allows early mobilization, more rapid return of normal function and has educational, social, psychological and economic advantage over the conservative management. It is also beneficial in patients with compound fractures, head injury, polytrauma. Internal fixation also leads to decrease in the incidence of malunion, nonunion and functionally important limb length discrepancy. It also satisfies many of the parents of the patients who insisted on perfect alignment at initial treatment 6 .

\section{References}

[1] Galpin RD, Willis RB, Sabano N. Intramedullary nailing of pediatric femoral fractures. J pediatric Orthop 1994; $14: 184-189$

[2] Kirby RM, Winquist RA, Hansen ST Jr. Femoral shaft fractures in adolescents: A comparison between traction plus cast treatment and closed intramedullary nailing. J Pediatr Orthop 1981; 1:193-197.

[3] Kumar Pradeep, Gaur SC, Srivastava DC, Vashishth Rohit Closed intramedullary K-wire fixation of femoral shaft fractures in children. Indian journal of Orthopaedics; 2001; 35; 242 - 244.

[4] Ligier JN, Metaizeau JP, Prevor J et al. Elastic stable intramedullary fixation of femoral shaft fractures in children.J Bone and Joint Surgery(Br) 1988;70:74-77.

[5] Mam M.K. John B. Fracture shaft of femur in children. Treatment and results. Indian Journal of Orthopaedics. 2001; 35No2: 28 - 30. 


\section{International Journal of Science and Research (IJSR) \\ ISSN (Online): 2319-7064}

Index Copernicus Value (2013): 6.14 | Impact Factor (2014): 5.611

[6] Mirdad Tarek: Operative treatment of femoral shaft fracture in children nine year experience in Saudi Arabian Population. INJURY 2003;31:769-771.

[7] Ozturkmen Y, Dogrul C, Karli M. intramedullary fixation of femoral shaft fractures in children with elastic Enders nail. Acta Orthoptraumatol turc.2002;36(3):2207.

[8] Pati B.N, Senthil Kumar V.A, Malik A.C, Gupta A.K Conservative management of femoral shaft fractures by 90-90 Traction in children - A review. Indian journal of orthopaedics 1997;31:36-40 